\title{
Usability Prototype Smart Portable Nebulizer for Self-care with Respiratory Disorders at Home
}

\author{
Qomariyatus Sholihah $^{1 *(D)}$, Dewi Hardiningtyas ${ }^{1}$ D, Kumoro Lenggono $^{2}$ D, Stephan Adriansyah Hulukati ${ }^{2}$, Wahyudi Kuncoro ${ }^{3}$, \\ Eko Tri Wisuda ${ }^{3}$ \\ ${ }^{1}$ Department of Industrial Engineering, Faculty of Engineering, University of Brawijaya Malang, Indonesia; ${ }^{2}$ Lecture and Doctoral \\ Program of Environmental Studies, Brawijaya University, Malang, Indonesia; ${ }^{3}$ Department of Medical, Student of the MMRS, \\ Brawijaya University, Malang, Indonesia
}

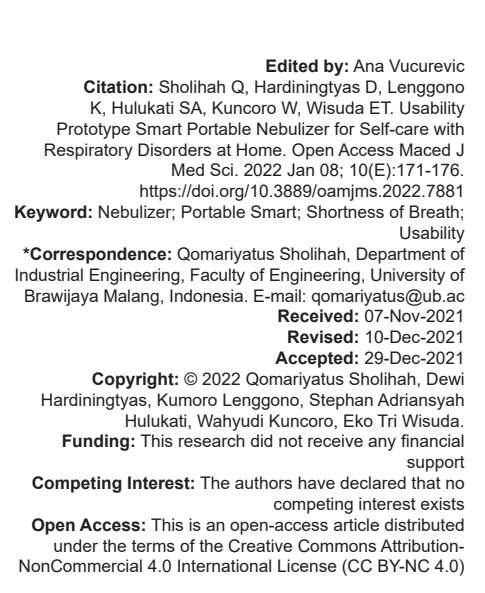

\section{Abstract}

BACKGROUND: The increasing prevalence of patients with shortness of breath due to asthma and chronic obstructive pulmonary disease requires the development of a nebulizer design that is easy, fast, inexpensive, and has reusability for sufferers in the community.

AIM: This study aims to design and assemble a prototype of a portable smart nebulizer for patients with respiratory disorders.

METHODS: The research design used an experimental approach with the design and assembly of a nebulizer which aims to analyze the operating results of the prototype of a portable smart nebulizer device with standard health calibration test equipment, and compare it with a mesh nebulizer as a control.

CONCLUSIONS: The prototype of the portable smart nebulizer had met the expected standard calibration of the instrument with the functioning of the component features of the device smartly, although it still requires improvement of the tool when used on patients.

\section{Introduction}

Since the first case of the COVID-19 pandemic in February 2020, it has caused more than 1.2 million cases and 3200 more deaths that occurred in various countries with respiratory infections, cough, increased temperatures, and life-threatening shortness of breath [1]. This has a very serious impact on the management and care of patients suffering from comorbid asthma [2] and chronic obstructive pulmonary disease at home with a high increase in cases [3] so that it requires appropriate political strategies and policies to prevent the spread of the virus and protect public safety in the community dealing with the COVID-19 pandemic [4].

Treatment management of patients with respiratory system disorders such as shortness of breath, coughing, and excessive accumulation of mucus using the principle of evaporation and fumigation using a nebulizer in the era of the COVID-19 pandemic is urgently needed in health services for patients in hospitals and families. Purpose of giving nebulizer therapy is to smooth the airway due to the accumulation shortness of breath, increase patient comfort and improve lung function in chronic obstructive pulmonary disease [5]. Studies and evaluations of the use of drugs and nebulizer therapy for patients are mostly carried out as an effort to increase the effectiveness and efficiency of the function of drugs and nebulizers for the recovery of patients, especially those who experience recurrence of asthma symptoms and chronic obstructive pulmonary disease [6], [7].

The current model of nebulizer tools is a nebulizer with an air compressor (nebulizer compressor) and a nebulizer that utilizes ultrasonic waves (ultrasonic nebulizer). The working principle of a nebulizer with an air compressor (nebulizer compressor) is to provide air pressure from the pipe to the lid (cup) containing liquid medicine. Air pressure will break the liquid into the form of small vapor particles that can be inhaled into the respiratory tract. The weakness of using a nebulizer compressor is because the tool does not use a timer control that is needed for patient safety and makes it easier for users to operate on patients.

The application of new drug innovations in nebulizer therapy such as the use of bronchodilators [8], 
corticosteroids, metered-dose inhalers [9], and adaptive aerosol development [10] plays an important role in the management of respiratory disorders in cases of chronic obstructive pulmonary disease during the COVID-19 pandemic. The development of the design of the nebulizer is useful for increasing the comfort of the patient in meeting the basic needs of the patient's respiratory function with asthma, and long chronic lung disease. This type of jet nebulizer is expensive [11]. However, in its use, there are obstacles to the drug evaporation process which is not controlled with a humidity indicator humidistat or hygrometer. In general, inhaled corticosteroid drugs mixed in an ultrasonic humidifier for long periods can cause side effects to patients, such as dry air, irritation, dry mouth, and sore throat from health facility services. At present, the development of nebulizer design has transformed into an effective and efficient nano nebulizer compared to jet nebulizer technology nebulizers.

The increasing use of nebulizer tools during the COVID-19 pandemic in hospitals and the community requires cheap and affordable nebulizer prices for families who cannot afford nebulizers. The development of smart portable nebulizer design with complete control features of temperature sensor, humidity or humidistat, flowmeter, and timer which expected to provide convenience and comfort effectiveness of drug function and low price is expected to provide smart solution for patients with respiratory disorders in the future.

The current model of nebulizer tools is a nebulizer with an air compressor (nebulizer compressor) and a nebulizer that utilizes ultrasonic waves (ultrasonic nebulizer). The working principle of a nebulizer with an air compressor (nebulizer compressor) is to provide air pressure from the pipe to the lid (cup) containing liquid medicine. Air pressure will break the liquid into the form of small vapor particles that can be inhaled into the respiratory tract. The weakness of using a nebulizer compressor is because the tool does not use a timer control that is needed for patient safety and makes it easier for users to operate on patients.

The application of new drug innovations in nebulizer therapy such as the use of bronchodilators [8], corticosteroids, metered-dose inhalers [9], and adaptive aerosol development [10] plays an important role in the management of respiratory disorders in cases of chronic obstructive pulmonary disease during the COVID-19 pandemic [11]. Including the development of the design of the nebulizer function as a useful tool for liquefying mucus due to accumulation of airway obstruction in people with asthma and chronic obstructive pulmonary disease. This type of jet nebulizer is expensive [12]. However, in its use, there are obstacles to the drug evaporation process which is not controlled with a humidity indicator humidistat or hygrometer. In general, inhaled corticosteroid drugs mixed in an ultrasonic humidifier for long periods can cause side effects to patients, such as dry air, irritation, dry mouth, and sore throat from health facility services. Currently, the development of nebulizer design has transformed into an effective and efficient nano nebulizer compared to jet nebulizer technology nebulizers.

The increasing use of nebulizer tools during the COVID-19 pandemic in hospitals and the community requires cheap and affordable nebulizer prices for families who can't afford nebulizers. Smart portable nebulizer with complete features of the temperature sensor, humidity/humidistat, flowmeter, and control timer which is expected to ensure safety, the convenience of use and effectiveness of medicine as well as low price tools for people with respiratory disorders such as asthma and chronic obstructive pulmonary disease.

\section{Methods}

This study uses an experimental research approach with the design and assembly of a nebulizer which aims to analyze the results of the operation of a portable smart nebulizer with standard health calibration test equipment and compare it with a mesh nebulizer as a control. The research stages consist of the hardware design process and software design.

\section{Hardware tools}

Tool hardware design by making prototype designs for portable smart nebulizer tools and research instrument equipment with parameters including the suitability of air humidity, temperature, and flow meter requirements. Testing of the portable smart nebulizer tool was carried out in the PT Surya Medical Service Surabaya laboratory by assessing, analyzing, and evaluating the results of using the tool by identifying the shortcomings and limitations of the tool.

\section{Software tools}

The device software consists of programming temperature, air humidity, and airflow monitoring tools to control the suitability of drug therapy needs and the effectiveness of drug work for patients to get maximum results in reducing shortness of breath complaints in patients.

\section{Calibration test}

The calibration test is a process of checking and setting the accuracy of the portable smart nebulizer tool by comparing standards referring to the Regulation of the Minister of Health of the Republic of Indonesia Number: 54 of 2015 concerning Testing and Calibration of Medical Devices [13]. Calibration is necessary to 
Table 1: Comparative test results of air flow pressure/steam flow calibration of the smart portable nebulizer tool with a mesh nebulizer (control)

\begin{tabular}{lllllll}
\hline Nebulizer Type & $1^{\text {st }} \mathrm{min}$ & $2^{\text {nd }} \mathrm{min}$ & $3^{\text {rd }} \mathrm{min}$ & $4^{\text {th }} \mathrm{min}$ & $5^{\text {th }}$ min & Unerage \\
\hline Mesh nebulizer (control) & 0.4 & 0.4 & 0.3 & 0.4 & 0.3 & 0.36 \\
Portable smart & 0.6 & 0.6 & 0.6 & 0.6 & 0.5 & 0.58 \\
\hline Standard nebulizer calibration water flow pressure is at least 0.3. & & & & Liter/minute \\
\end{tabular}

Standard nebulizer calibration water flow pressure is at least 0.3 .

ensure that the results of measurements or inspections carried out by the instrument are accurate and consistent with other instruments. Medical devices for which testing and/or calibration are performed are equipment used for diagnosis, therapy, rehabilitation, and medical research, either directly or indirectly, and have parameters of appointment, output, or performance. The aim is to ensure the availability of medical devices following service standards, quality requirements, security, benefits, safety, and suitability for use in health service facilities and other health facilities and to increase accountability and service quality of health facility testing centers and health facilities testing institutions in testing and medical device calibration.

\section{Results}

\section{patients \\ Design of smart portable nebulizer for}

A controller is a tool that functions to control a device in the form of a microcontroller that uses Arduino Nanotechnology which is small and simple, making it easier for patients to use the nebulizer (Figures 1-3). The temperature sensor is a sensor that functions to monitor the air temperature in degrees Celsius when the airflow evaporates the drug from the nebulizer when it enters the nostril of the patient who uses a nasal cannula or mask. There is an LCD screen to display information about the state of temperature, humidity, airflow, and battery status (Figure 4).

Table 2: Comparative test results of the temperature and humidity calibration of the smart portable nebulizer with a mesh nebulizer (control)

\begin{tabular}{lll}
\hline Nebulizer type & Temperature & Air humidity \\
\hline Mesh nebulizer (control) & - & - \\
$\begin{array}{l}\text { Nebulizer portable } \\
\text { smart }\end{array}$ & $27.2^{\circ} \mathrm{C}$ & $52 \%$ \\
\hline Standard nebulizer temperature is $27^{\circ} \mathrm{C}$ and humidity $50 \%$. & \\
\hline
\end{tabular}

The humidity sensor section is a monitoring tool to control the state of the humidity of the air flowing from the nebulizer. The airflow sensor is a sensor used to monitor the flow rate or volume of air in liters/minutes that flow from the nebulizer. There is an LCD screen to display information about the state of temperature, humidity, airflow, and battery status (Figure 4). Ultrasonic humidifier is a water vapor generator utilizing ultrasonic waves in the form of bursts of evaporation from the heating effect or warming a mixture of medicine and water. Air heater is a heater to heat the air from the nebulizer to fit the needs. The air pump is to pump air to flow with a discharge that can be adjusted to the needs.
Asthma medicines and sterile water mixers are medicines for asthmatics prescribed by doctors and water injection/aqua bikes as a medicine mixer that is inserted into a container connected to an ultrasonic humidifier and a micro-universal serial bus port that can be connected to a power bank so that it can be used at any time outside the reach of a power source.

\section{Nebulizer test result with calibration}

Based on Table 1, the average results of the calibration test for water pressure for/steam flow of both nebulizer tools have met the minimum standard above 0.3 liters/minute.

Standard nebulizer temperature is $27^{\circ} \mathrm{C}$ and humidity $50 \%$

Based on Table 2, it is found that the small nebulizer does not have temperature and humidity indicators so that the results cannot be observed. The result of temperature calibration measurements on a smart portable nebulizer are $27.2^{\circ} \mathrm{C}$ and humidity is $52 \%$.

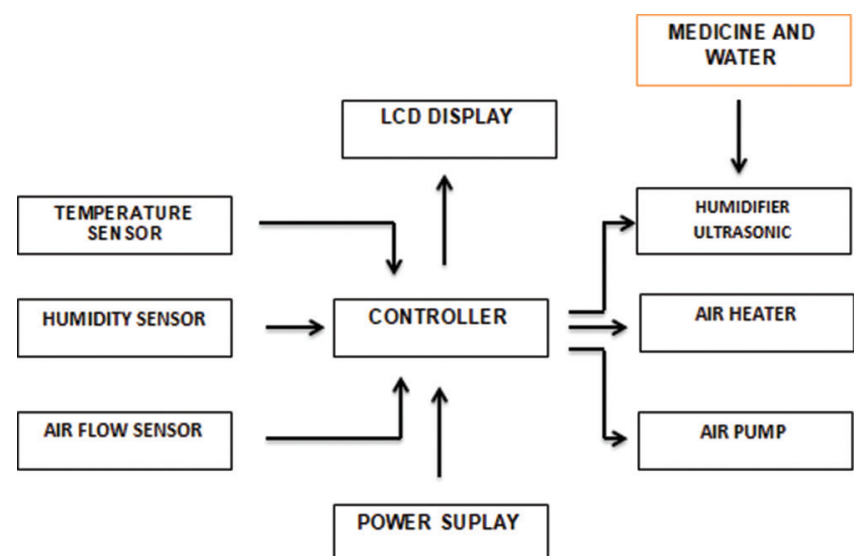

Figure 1: Component design of a portable smart nebulizer tool [26]

\section{Discussion}

The incidence of recurrent attacks of asthma with symptoms of shortness of breath occurs on average 2.56/1000 people per year. These cases are increasing in children under 10 years of age with an incidence rate of $4.38 / 1000$ people per year [14]. This can be risky in the initial treatment of shortness of breath away from health-care centers such as community health centers or hospitals. Meanwhile, the use of nebulizers is currently increasing during the COVID-19 pandemic and is not 


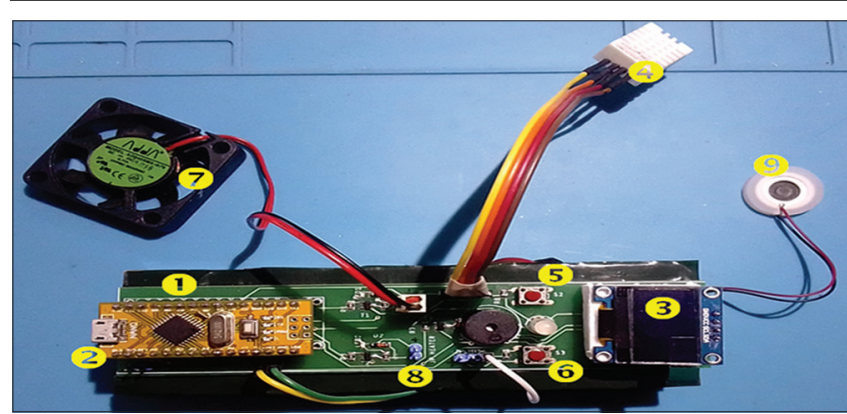

Figure 2: Assembling the components of the portable smart nebulizer tool (add the front) (1) The main board of the tool: The main board where all the components are installed. (2) Arduino nano: Device controller. (3) 0.96-inch OLED Display: LCD viewer with $128 \times 64$ pixels. Resolution (4) DHT22 sensor: Temperature and humidity sensor. (5) Tactile button 1. (6) Tactile button 2. (7) Fan: A fan to regulate the flow of heat in the nebulizer channel. (8) Heater connector: A connector for the air heater in the nebulizer duct. (9) Ultrasonic mist maker plate: Ultrasonic fumigating mist making plate [26].

sufficient for the general public [15], [16]. In general, the provision of therapy using a nebulizer is mostly given to asthmatics who need continuous care during an attack of shortness of breath. The frequency of administration can be done 6 times a day of nebulizer therapy. The type of jet nebulizer is the type most widely used in the treatment of shortness of breath in asthma, but the nebulizer is still in the category of expensive and less efficient for the use of certain drugs [17]. This situation can worsen and threaten the patient's safety when an attack occurs because of the limitations of nebulizer equipment and the unaffordability of prices for people with low economies.

The main health problem in patients with asthma is the ineffectiveness of the airway which is characterized by a hypersensitive response which is characterized by the patient experiencing excessive mucus production of the respiratory tract which causes shortness of breath [18]. The occurrence of sudden shortness of breath can occur outside the reach of health services such as hospitals and can pose a risk to the patient's safety. The prevalence of shortness of breath is increasing by $10 \%$ in the patient care population at home and nursing homes. The impact of the prevalence of shortness of breath causes a decrease in meeting the needs of daily activities such as going, drinking, bathing, movement, and socialization [19].

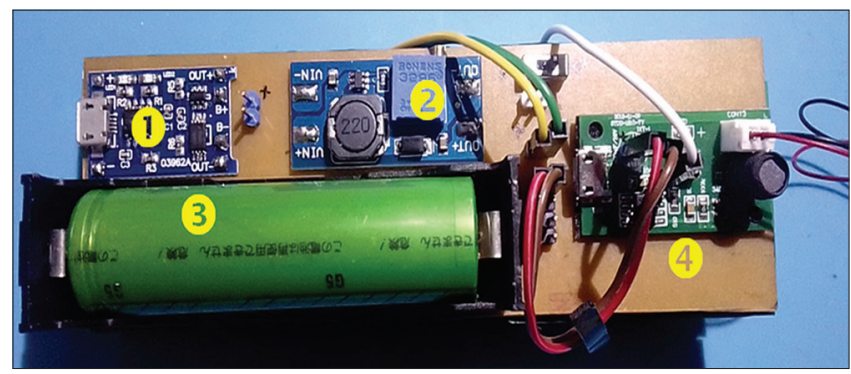

Figure 3: Assembly of the portable smart nebulizer tool components (rear view). (1) Changer module: 18650. Battery charger component. (2) Step up module: Battery voltage booster component from $3.7 \mathrm{~V}$ to 5 V. (3) 18650 battery and holder: 3.7 V 18650 battery and holder. (4) Ultrasonic mist maker module: Component of ultrasonic fumigation mist maker [26]
The development of designs such as the OMRON A3 nebulizer model has provided good efficacy and reusability to produce aerosols in the treatment of asthma patients with particle diameters of 2-4.5 m, 4.5-7.5 m, or $>7.5 \mathrm{~m}$ in the case of children aged 5-4.5 $\mathrm{m}$ [20].

Figure 5, the prototype of this smart portable nebulizer is designed as a nebulizer that is easy, safe, and fast using component features that increase reusability for sufferers and first aid in the event of a sudden attack. The presence of a temperature and humidity sensor component on the device helps the user to monitor the suitability of the heat needs of the ultrasonic stream that flows into the sufferer's nose. The temperature and humidity of the air outside the body can increase the hypersensitivity response to the occurrence of shortness of breath attacks. The prototype of a smart portable nebulizer which is equipped with control and regulation of air temperature and humidity helps improve the function of the mucous membrane in regulating the humidity of the air flowing in the respiratory tract so that it can increase the effect of the drug and the comfort of the patient sufferer.

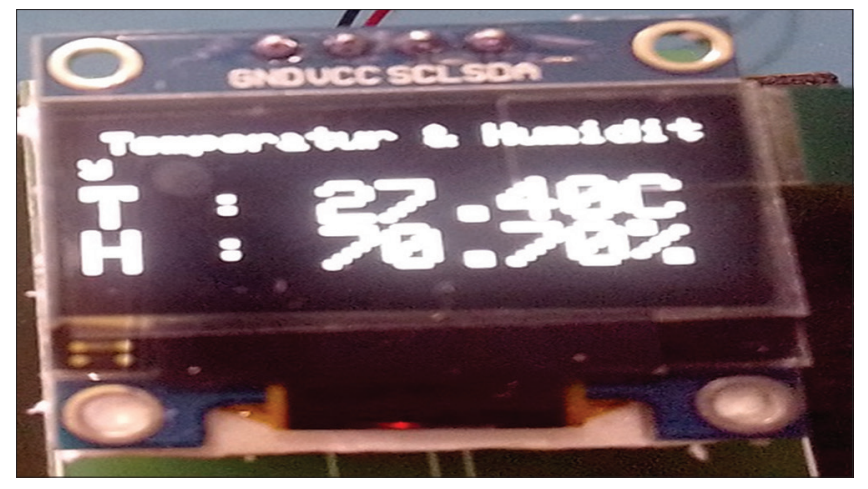

Figure 4: Liquid crystal display readings of temperature, humidity, and airflow [26]

Humidity sensors are very important to determine the suitability of the outside and inside air, the warmth of the air temperature when it enters the patient's nose which can have a positive effect on people with dyspnea, such as those who are hypersensitive to changes in cold air, allergens, or the patient's psychological state so that they can adapt to physiology and psychology responses. Some models of nebulizer products are not equipped with a humidifier sensor control as a humidity measuring device, such as a humidistat or hygrometer [11]. This makes us need to check the humidity in the room manually so that the humidity is maintained in the body. Complaints of dry mouth and sore throat can occur in the use of a saline nebulizer so it needs to be monitored [21].

The control of the steam air flow meter on the smart portable nebulizer is very necessary according to the patient's needs. In general, patients have their own sensitivity and comfort in receiving air volume pressure, sometimes too large a flow can make the patient uncomfortable with his needs with a nebulizer so that 


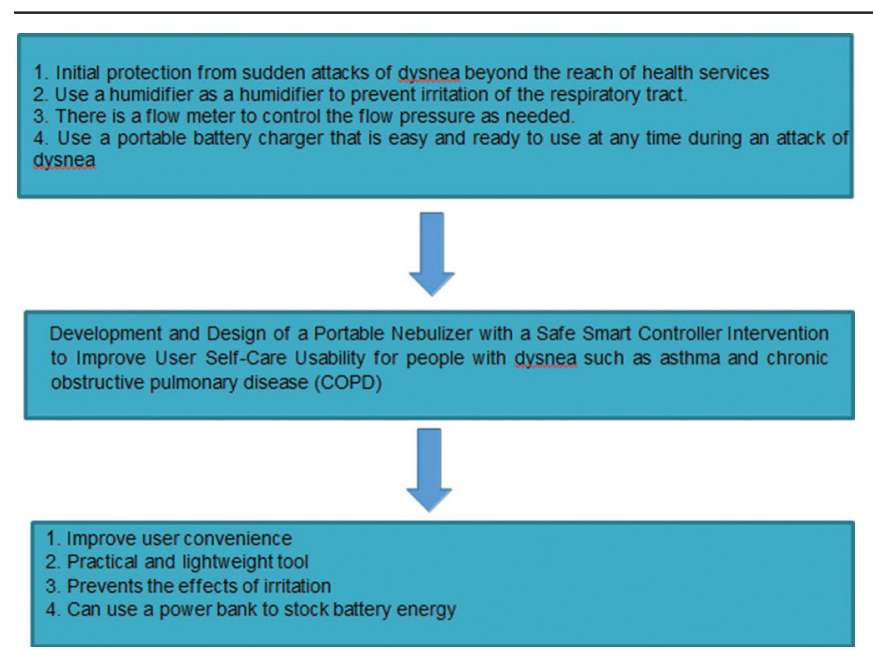

Figure 5: Benefits of designing a smart portable nebulizer for patients with shortness of breath [26]

the patient can control the volume flow requirement according to the patient's wishes. This needs to be done to ensure that the equipment installation can function properly as expected by the needs of the drug and the user. The components of the smart portable nebulizer have convenience features for patients such as a flow meter control, temperature and humidity display, medicine holder and battery charger energy. The use of a nebulizer must consider the infection prevention aspect, considering that non-hygienic nebulizer treatment causes the development of microorganisms that can spread infectious germs to patients [22], thus requiring training, adherence to procedures and care for patients and their families [23], [24].

In the results of the calibration trial, the portable smart nebulizer prototype with a mesh nebulizer (control) meets low-pressure standards and can be used for therapy in patients with respiratory problems, especially for initial help in the family or community. The airflow pressure in the smart portable nebulizer is stronger with an average of $0.58>0.3$ liters/minute per minute, while the mesh nebulizer (control) has an average airflow pressure of $0.36>0.3$ liters/minute. While the results of temperature and humidity calibration are still not following the standard, considering that the portable smart nebulizer has not yet been printed on the packaging or box, so that it is possible to have the influence of temperature and humidity from the surrounding air, so it requires repairs to do a temperature and humidity calibration test again. In addition, it still requires improvement of the temperature and humidity program settings again to suit the needs.

This is very important considering that the output temperature and humidity of the nebulizer equipment are following the physiological needs of respiration, which greatly helps the adaptation of the respiratory process environment and helps improve the function of nebulizer drugs to dilute and remove airway obstructions in the throat and bronchi due to secretions or excessive mucus production. In the future, this smart portable nebulizer tool needs to be tested, such as in the management of combination prescribing drugs using a nebulizer in various cases of lung disease. Many cases of lung disease have been developed to help reduce shortness of breath in patients by considering the negative effects and benefits of drugs for sufferers [11], [20], [25].

Thus, the prototype of this smart portable nebulizer is expected to be able to help practically, effectively, and efficiently as first aid for patients who experience shortness of breath or airway disorders due to accumulation of mucus secretions in the airways due to inflammation or allergic hypersensitivity at home or in the community.

\section{Conclusions}

The prototype of the smart portable nebulizer has met the expected standard of tool calibration with the functioning of the component features of the tool smartly, although it still requires tool refinement when used on patients. In the future, the innovation of developing these tools needs to be tested on patients with shortness of breath or respiratory problems while still referring to the doctor's prescription.

\section{References}

1. Binns C, Low WY, Kyung LM. The COVID-19 pandemic: Public health and epidemiology. Asia Pac J Public Health. 2020;32(4):140-4. https://doi.org/10.1177/1010539520929223 PMid:32429675

2. Lee SC, Son KJ, Han CH, Jung JY, Park SC. Impact of comorbid asthma on the severity of coronavirus disease (COVID-19). Sci Rep. 2020;10(1):21805. https://doi.org/10.1038/ s41598-020-77791-8

PMid:33311519

3. Ari A, Blain K, Soubra S, Hanania NA. Treating COPD patients with inhaled medications in the era of covid-19 and beyond: Options and rationales for patients at home. Int J Chron Obstruct Pulmon Dis. 2021;16:2687-95. https://doi.org/10.2147/COPD. S332021

PMid:34611397

4. Haryono BS, Sholihah Q, Hidayati F, Ahmadi B, Lenggono KA Doctoral $S$, et al. The role of politics and policy strategy in facing a COVID-19 pandemic: Case study in Indonesia. Rev Int Geogr Edu. 2021;11:3833-9.

5. Milestone AP. Nebulized therapies in COPD: Past, present, and the future. Int J Chron Obstruct Pulmon Dis. 2020;15:1665-77. https://doi.org/10.2147/COPD.S252435 PMid:32764912

6. Guidance for Nebulization During the COVID19 Pandemic 2021.

7. Online E, Park HM, Chang KH, Moon SH, Park BJ, Yoo SK. In vitro delivery efficiencies of nebulizers for different breathing 
patterns. Biomed Eng Online 2021;20(1):59. https://doi. org/10.1186/s12938-021-00895-3

PMid:34112170

8. Weatherby $\mathrm{H}$, Bernstein A. A long-term prospective assessment of home nebulizer treatment. Respir Med. 1992;86(4):317-25. https://doi.org/10.1016/s0954-6111(06)80031-4 PMid: 1448587

9. Chilkoti GT, Gondode PG, Tiwari SS. MDI or nebulization in moderate to severe COVID-19 disease with COPD: Which one is better? Ain-Shams J Anesthesiol. 2021;13(1):24. https://doi. org/10.1186/s42077-021-00148-4

10. Press D. A review of nebulized drug delivery in COPD. Int $J$ Chron Obstruct Pulmon Dis. 2016;11:2585-96. https://doi. org/10.2147/COPD.S114034 PMid:27799757

11. Dhand R, Dolovich M, Eng P, Chipps B, Myers TR, Restrepo R, et al. The role of nebulized therapy in the management of COPD: Evidence and recommendations. COPD. 2012;(6):58-72. https://doi.org/10.3109/15412555.2011.630047 PMid:22292598

12. Kumar M, Kumar S. Development of the Low-Cost Portable Ultrasonic Nebulizer in COVID 19 Era: DIY Nano Nebulizer; 2021.

13. Huda C, Nugraha PC, Pudji A. Perancangan Alat Bantu Kalibrasi Doppler Tanpa Display Pada LPFK Banjarbaru No. 60282; 2018.

14. De Marco R, Locatelli F, Cerveri I, Bugiani M, Marinoni A, Giammanco G, et al. Incidence and remission of asthma: A retrospective study on the natural history of asthma in Italy. J Allergy Clin Immunol. 2002;110(2):228-35. https://doi. org/10.1067/mai.2002.125600

PMid:12170262

15. Öztürk AB, Baccioğlu A, Soyer ÖU, Civelek E. Pros and cons of nebulizer treatment in asthma exacerbation during the COVID-19 pandemic. Asthma Allergy Immunol. 2021;(3):2-6.

16. Dziublyk YO, Bororova OL, Patiuk YO. Expediency and Safety of Nebulizer Therapy No. 38044; 2020.

17. Bartho M, Breshock M, Nolte M. NebuFlask: Advancing Usability of Nebulizers to Increase Patient Compliance; 2019.

18. Karasu F, Birimoğlu C. The effect of nursing care applied to patients with chronic obstructive pulmonary disease on their sexual experiences and quality of life. Sex Disabil. 2021;39(3):529-42. https://doi.org/10.1007/s11195-021-09677-0
19. Seow H, Dutta $P$, Johnson MJ, Mcmillan K, Guthrie DM, Costa AP, et al. Prevalence and risk factors of breathlessness across Canada: A national retrospective cohort Study in home care and nursing home populations. J Pain Symptom Manage. 2021;62(2):346-54.e1. https://doi.org/10.1016/j. jpainsymman.2020.11.034 PMid:33276042

20. Greene G, Costello RW, Greene G, Costello RW. Expert opinion on drug delivery personalizing medicine-could the smart inhaler revolutionize treatment for COPD and asthma patients ? Expert Opin Drug Deliv. 2019;16(7):675-7. https://doi.org/10.1080/174 25247.2019.1628017

\section{PMid:31177857}

21. Le T, van Nguyen $P$, Wilkinson $D$, van Nguyen $P$, Wilkinson $D$. Nebulized saline produced by ultrasonic humidifiers should be considered as an option for COVID-19. Immunome Res. 2021;17(5):1-3. Available from: http://www.0-search. proquest.com.pugwash.lib.warwick.ac.uk/scholarlyournals/nebulized- saline-produced-ultrasonic-humidifiers/ docview/2557266917/se-2?accountid=14888\%0a; http://www. webcat. warwick.ac.uk:4550/resserv??genre=article\&issn= 17457580\&title=Immunome+Resea. [Last accessed on 2021 Sep 08].

22. Yegit $\mathrm{CY}$. The effects of nebulizer hygiene training on the practices of cystic fibrosis patients and caregivers. Pediatr Pulmonol. 2021;56(6):1527-33. https://doi.org/10.1002/ ppul.25307

PMid:33538406

23. Rasulova NA, Irbutaeva LT. The Effectiveness of Nebulizer Therapy in Broncho Obstructive, CAJMNS; 2021. p. 178-81.

24. Turner J, Wright E, Mendella L, Anthonisen N. Predictors of patient adherence to long-term home nebulizer therapy for COPD. The IPPB Study Group. Intermittent positive pressure breathing. Chest. 108(2):394-400. https://doi.org/10.1378/ chest.108.2.394

PMid:7634873

25. Sayed NE, Abdelrahman MA, Abdelrahim ME. Effect of functional principle, delivery technique, and connection used on aerosol delivery from different nebulizers: An in-vitro study. Pulm Pharmacol Ther. 2021;70:102054. https://doi.org/10.1016/j. pupt.2021.102054 PMid:34280581

26. Brawijaya University. The Results of the Design of a Smart Portable Nebulizer, Department of Industrial, Faculty of Engineering. Indonesia: Brawijaya University; 2021. 